\title{
Preregistration rotation including general practice at St Mary's Hospital Medical School
}

\author{
C M HARRIS, H A F DUDLEY, B JARMAN, P H KIDNER
}

\begin{abstract}
A rotation for the preregistration year which included medicine, surgery, and general practice started at St Mary's Hospital Medical School in August 1981. Initially approved by London University for an experimental period of three years, in 1984 it became an established rotation subject to normal review.

Special arrangements were made for clinical work, supervision, prescribing, teaching, and other aspects of the general practice component. Data relating to the general practice consultations of the nine participating house officers show that they obtained wide experience, and their comments on the post itself were generally favourable. The four months spent in general practice were needed to allow time for the house officers to adapt to the new setting but did not seem to have an important effect on their experience in medicine and surgery.
\end{abstract}

\section{Introduction}

Of the 2877 preregistration house officers in post on 30 September 1981 , one was working in general practice. He was in a rotation which included medicine, surgery, and general practice, with four months in each discipline, and which had started at St Mary's Hospital and Medical School in August that year. The hospital posts had been training junior house officers for many years; the new component was organised by the school's department of general practice and based on a practice housed in the same health centre premises. The rotation was an educational experiment approved for three years.

The preparatory work had posed academic, legal, and administrative problems, which took nearly four years to overcome. In that time the scheme had gained the backing of the medical school, the hospital, the North West Thames regional preregistration subcommittee, the University of London, the defence organisations, the local medical committee, the family practitioner committee, and undergraduate opinion. The regional health authority agreed to fund an additional preregistration year and to make a small payment to the hospital to ensure that the house officers would retain their living accommodation in the hospital while they were working in the practice. The special trustees of St Mary's Hospital leased a car for three years and underwrote all expenses other than the cost of petrol and oil; the only restriction they imposed was that its use in each year should not exceed 7000 miles.

\section{St Mary's Hospital Medical School, London W2}

C M HARRIS, MED, FRCGP, senior lecturer, department of general practice H A F DUDLEY, CHM, FRCS, professor, academic surgical unit B JARMAN, PHD, FRCGP, professor, department of general practice

P H KIDNER, MA, FRCP, honorary lecturer and head of Waller cardiac department

Correspondence to: Dr Harris, Department of General Practice, Lisson Grove Health Centre, Gateforth St, London NW8.
Approval by London University was granted subject to favourable reports by the regional postgraduate dean after one year and towards the end of three years.

\section{Methods}

The three posts were included together in the annual computer matching program for final year students at the medical school. Both hospital firms were in the main teaching hospital: surgery on the professorial unit and medicine on a firm with a special interest in cardiothoracic medicine; the general practice was in Lisson Grove Health Centre. Selection was made after interview; we gave considerable preference to candidates who did not intend to go into general practice as a career and we insisted on the possession of a driving licence.

\section{THE PRACTICE}

In 1981 the practice had about 6000 patients, with three partners, a part time doctor, a trainee, and full supporting staff both employed and attached. No deputising service was used by the supervising doctor. With subsequent growth a fourth partner was appointed. Once the scheme began the practice stopped taking medical students. The house officer shared a consulting room with the trainee; while one consulted, the other had home visits or other duties to undertake.

The house officer was on duty from 0900 to 1900 each weekday, with two nights a week and one weekend in four on call. This corresponded to a basic working week of 40 hours with an additional $12 \mathrm{~A}$ units of medical time. He or she (only one of the nine was a woman) had seven consulting sessions a week, taken alone after a brief initial period of sitting in, one session in the treatment room, and one session attending a well baby clinic.

The supervising practitioner or a partner was always available immediately to give advice while the house officers' surgeries were being held, and a brief review of the patients seen usually took place afterwards. All unaccompanied home visits were considered individually by a partner before being allocated to the general practice house officer; a partner was always available by telephone or radiopager in case of difficulty; a report was made to the partner afterwards; and admitting a patient to hospital without consulting a partner was not allowed except in an emergency.

Initially the house officer had a few presigned FPl0 forms given to him before each surgery and kept carbon copies of his prescriptions to discuss with a partner immediately afterwards. Though there were precedents for this arrangement, its legality was in doubt, and a different system was introduced halfway through the attachment of the eighth house officer, which gave him a choice. He could get a prescription signed immediately; arrange for it to be collected after the surgery was over; or make use of a small permitted stock of drugs to cover the first 24 hours of treatment. This system, which was also applied to home visiting, was cumbersome but not unworkable. It brought about a fall in the general practice house officers' prescribing rates (table II) and did not ever need to operate more than about six times in any consulting session. The stock of drugs was supplied by the hospital pharmacy.

Our plan to select a number of patients for each house officer to review fully proved to be impracticable; instead, he accompanied the supervising doctor on the routine "chronic sick round" of visits and was given responsibility for the management of some of the patients they saw. 
TEACHING

In addition to the informal daily discussion of patients seen in the surgery and at home, up to two hours of formal teaching per week were given by the supervising doctor or partner. Some time was spent with nursing, physiotherapy, and marriage guidance staff working in the health centre; and the house officer attended the weekly lectures held in the building for all staff. Once a week there was a tutorial in the department, usually on a subject suggested by a current problem in the clinical work and most commonly to do with difficulties in relating to particular patients. Attending sessions of the trainees' half day release course was abandoned because this clashed with the chronic sick visiting round. The library of the department was available to the general practice house officers and used frequently.

\section{HOSPITAI. LIAISON}

Living in hospital accommodation kept the general practice house officers in daily contact with their contemporaries, a feature which was regarded as very important. When patients with whom the house officers were concerned were admitted to the wards it was natural to visit them there, and some who had been seen by the house officer when he was working in the hospital were later encountered in the practice.

\section{Results}

All doctors in the practice use encounter forms in their consultations so that recorded data can be later coded and put on computer. The general practice house officers' coding was initially done by departmental research staff, but the last three had to do their own. They agreed that this made them think more precisely about their diagnoses and familiarised them with the international classification of diseases, but they did not like the task.

Tables I-III indicate the range of experience obtained by the nine house officers. Table IV displays the frequency of consultations for certain

TABLE I-Total number of consultations held by each general practice house officer in four months, with number of home visits made

\begin{tabular}{lccccccccc}
\hline House officer: & 1 & 2 & 3 & 4 & 5 & 6 & 7 & 8 & 9 \\
\hline All consultations & 794 & 818 & $6 \times 2$ & 697 & 644 & 818 & 841 & 979 & 714 \\
Home visits & 110 & 133 & 126 & 114 & 102 & 153 & 154 & 224 & 103 \\
\hline
\end{tabular}

TABLE II - V'arious outcomes of consultations held by each general practice house officer

\begin{tabular}{|c|c|c|c|c|c|c|c|c|c|}
\hline House officer: & 1 & 2 & 3 & 4 & 5 & 6 & 7 & 8 & 9 \\
\hline Follow up arranged $(\%)$ & $\begin{array}{r}2 \cdot 9 \\
57 \cdot 4\end{array}$ & $\begin{array}{r}1 \cdot 6 \\
68 \cdot 2\end{array}$ & $\begin{array}{l}14.2 \\
55.9\end{array}$ & $\begin{array}{l}24.5 \\
56.5\end{array}$ & $\begin{array}{r}9 \cdot 5 \\
51 \cdot 2\end{array}$ & $\begin{array}{l}37.8 \\
51.5\end{array}$ & $\begin{array}{l}27 \cdot 8 \\
50 \cdot 4\end{array}$ & $\begin{array}{l}16 \cdot 9 \\
47 \cdot 7\end{array}$ & $\begin{array}{l}11 \cdot 9 \\
37 \cdot 0\end{array}$ \\
\hline \\
\hline $\begin{array}{l}\text { Xay investigations ordered } \\
\text { Laboratory investigations ordered }\end{array}$ & $\begin{array}{ll}+3 \\
64\end{array}$ & $1^{*}$ & $\begin{array}{l}11 \\
56\end{array}$ & $\begin{array}{l}43 \\
86\end{array}$ & $\begin{array}{l}18 \\
52\end{array}$ & $\begin{array}{l}28 \\
62\end{array}$ & $\begin{array}{l}36 \\
97\end{array}$ & $\begin{array}{r}43 \\
149\end{array}$ & $\begin{array}{l}22 \\
93\end{array}$ \\
\hline Outpatient appointments made & 18 & $5 *$ & 23 & 35 & 14 & 26 & 42 & 32 & 41 \\
\hline $\begin{array}{l}\text { Sent to accident and emergency } \\
\text { department }\end{array}$ & l & 5 & 3 & 2 & 3 & 1 & 13 & 5 & 5 \\
\hline Admitted to hospital & 0 & $3 t$ & $i$ & 0 & 7 & it & 7 & 4 & 3 \\
\hline
\end{tabular}

- Recording incomplete.

t Including one to the lixal GP hospital.

conditions chosen as examples of major acute illness, chronic illness, minor acute physical illness, psychological illness, preventive care, and symptoms of uncertain origin. Some of the variation among house officers seen in these tables is due to chance or external circumstance, but in part it reflects differences in their personalities - a finding which is typical of data from general practice.

The commentaries written by the general practitioner house officers at the end of the four months all deal with largely the same themes and express very similar views. The quotations which follow are typical:

On supervision-" It was certainly a far more demanding job than I had expected. I was given as much responsibility as I wished, with the knowledge that if I had any problems or difficulties I could enlist the help of any of the others in the practice."

On prescribing - "I found this angle of the job one of the more taxing as I constantly thumbed the British National Formulary for advice. As time progressed I established my own pharmacopoeia and enjoyed the challenge."

On clinical experience- "Home visiting allowed me to see the majority of the (serious) acute medicine I saw in four months." "I was presented with a wealth of pathology." "Many psychiatric problems were seen, especially among the temporary residents." "I soon built up quite a substantial list of chronically ill patients whom I attended regularly at home." "The range of duties undertaken by the team was a complete new world."

On departmental tutorials_- "The more relaxed sessions allowed ideas to be explored in more depth." ". . . enabled me to alter the pattern of an interview and to try to unearth the real anxieties. This was especially helpful when dealing with home visits at night."

TABL.E III-Percentages of fiv' age groups of patients seen by each general practice house officer

\begin{tabular}{lrrrrrrrrr}
\hline House officer: & 1 & 2 & 3 & 4 & 5 & 6 & 7 & 8 & 9 \\
\hline Years: & & & & & & & & & \\
0.4 & $12 \cdot 1$ & $14 \cdot 1$ & $14 \cdot 5$ & $12 \cdot 7$ & $15 \cdot 2$ & $12 \cdot 0$ & $10 \cdot 0$ & $12 \cdot 6$ & $12 \cdot 3$ \\
$55 \cdot 14$ & $8 \cdot 7$ & $9 \cdot 9$ & $11 \cdot 8$ & $7 \cdot 8$ & $12 \cdot 0$ & $8 \cdot 5$ & $9 \cdot 0$ & $10 \cdot 9$ & $12 \cdot 1$ \\
$15 \cdot 6 \cdot 4$ & $64 \cdot 8$ & $62 \cdot 8$ & $58 \cdot 3$ & $65 \cdot 1$ & $62 \cdot 0$ & $59 \cdot 1$ & $67 \cdot 6$ & $60 \cdot 8$ & $65 \cdot 3$ \\
$65-74$ & $9 \cdot 7$ & $8 \cdot 0$ & $7 \cdot 8$ & $6 \cdot 3$ & $4 \cdot 1$ & $8 \cdot 3$ & $6 \cdot 2$ & $7 \cdot 4$ & $4 \cdot 6$ \\
$\geqslant 75$ & $4 \cdot 7$ & $5 \cdot 2$ & $7 \cdot 6$ & $8 \cdot 1$ & $6 \cdot 7$ & $12 \cdot 1$ & $7 \cdot 2$ & $8 \cdot 3$ & $5 \cdot 7$
\end{tabular}

TABLE IV - Number of consultations for selected conditions held by each general practice house officer with total numbers of diagnoses recorded and ICD codes used

\begin{tabular}{|c|c|c|c|c|c|c|c|c|c|}
\hline House officer: & 1 & 2 & 3 & 4 & 5 & 6 & 7 & 8 & 9 \\
\hline $\begin{array}{l}\text { Acute myecardial infarction } \\
\text { Acute cerebrovascular accident } \\
\text { Acute appendicitis } \\
\text { Acute intestinal obstruction }\end{array}$ & $\begin{array}{l}0 \\
0 \\
0 \\
0\end{array}$ & $\begin{array}{l}5 \\
2 \\
0 \\
0\end{array}$ & $\begin{array}{l}1 \\
0 \\
1 \\
1\end{array}$ & $\begin{array}{l}0 \\
5 \\
0 \\
1\end{array}$ & $\begin{array}{l}1 \\
1 \\
1 \\
0\end{array}$ & $\begin{array}{l}1 \\
0 \\
0 \\
0\end{array}$ & $\begin{array}{l}1 \\
1 \\
0 \\
0\end{array}$ & $\begin{array}{l}8 \\
0 \\
2 \\
0\end{array}$ & $\begin{array}{l}0 \\
0 \\
0 \\
0\end{array}$ \\
\hline $\begin{array}{l}\text { Asthma } \\
\text { Diabetes } \\
\text { Peptic ulcer } \\
\text { Chronic heart discase } \\
\text { Chronic bronchitis and obstructive } \\
\text { airways disease }\end{array}$ & $\begin{array}{r}14 \\
3 \\
18 \\
6\end{array}$ & $\begin{array}{r}25 \\
3 \\
8 \\
6\end{array}$ & $\begin{array}{r}19 \\
11 \\
6 \\
11\end{array}$ & $\begin{array}{r}12 \\
4 \\
6 \\
17\end{array}$ & $\begin{array}{r}14 \\
2 \\
0 \\
16\end{array}$ & $\begin{array}{r}9 \\
2 \\
2 \\
19\end{array}$ & $\begin{array}{r}19 \\
10 \\
4 \\
18\end{array}$ & $\begin{array}{l}15 \\
1 \\
13 \\
23\end{array}$ & $\begin{array}{r}13 \\
5 \\
11 \\
5\end{array}$ \\
\hline Arthritis & 11 & 8 & 18 & 7 & 7 & 26 & 14 & 12 & 7 \\
\hline $\begin{array}{l}\text { Gastroenteritis } \\
\text { Otitis media }\end{array}$ & $\begin{array}{l}26 \\
20\end{array}$ & $\begin{array}{l}25 \\
20\end{array}$ & $\begin{array}{l}30 \\
27\end{array}$ & $\begin{array}{r}19 \\
9\end{array}$ & $\begin{array}{l}29 \\
16\end{array}$ & $\begin{array}{r}30 \\
5\end{array}$ & $\begin{array}{l}30 \\
18\end{array}$ & $\begin{array}{l}24 \\
29\end{array}$ & $\begin{array}{r}24 \\
8\end{array}$ \\
\hline $\begin{array}{l}\text { Anxiety states } \\
\text { Depression }\end{array}$ & $\begin{array}{l}19 \\
17\end{array}$ & $\begin{array}{l}+4 \\
10\end{array}$ & $\begin{array}{r}9 \\
12\end{array}$ & $\begin{array}{l}34 \\
29\end{array}$ & $\begin{array}{l}23 \\
10\end{array}$ & $\begin{array}{r}6 \\
21\end{array}$ & $\begin{array}{r}18 \\
7\end{array}$ & $\begin{array}{l}30 \\
31\end{array}$ & $\begin{array}{r}21 \\
3\end{array}$ \\
\hline $\begin{array}{l}\text { Hypertension } \\
\text { Contraception } \\
\text { Antenatal care } \\
\text { Immunisation }\end{array}$ & $\begin{array}{r}19 \\
18 \\
7 \\
9\end{array}$ & $\begin{array}{r}13 \\
22 \\
4 \\
0\end{array}$ & $\begin{array}{r}12 \\
13 \\
9 \\
0\end{array}$ & $\begin{array}{r}27 \\
20 \\
10 \\
0\end{array}$ & $\begin{array}{r}10 \\
13 \\
1 \\
5\end{array}$ & $\begin{array}{r}19 \\
28 \\
7 \\
0\end{array}$ & $\begin{array}{r}9 \\
35 \\
7 \\
2\end{array}$ & $\begin{array}{r}13 \\
37 \\
11 \\
0\end{array}$ & $\begin{array}{r}12 \\
28 \\
5 \\
1\end{array}$ \\
\hline $\begin{array}{l}\text { Abdominal pain } \\
\text { Chest pain }\end{array}$ & $\begin{array}{l}26 \\
13\end{array}$ & $\begin{array}{l}3 \\
2\end{array}$ & $\begin{array}{r}13 \\
6\end{array}$ & $\begin{array}{r}13 \\
6\end{array}$ & $\begin{array}{r}19 \\
9\end{array}$ & $\begin{array}{r}11 \\
9\end{array}$ & $\begin{array}{l}17 \\
11\end{array}$ & $\begin{array}{l}32 \\
16\end{array}$ & $\begin{array}{r}34 \\
9\end{array}$ \\
\hline $\begin{array}{l}\text { No of all diagnoses made } \\
\text { No of ICD codes used }\end{array}$ & $\begin{array}{l}905 \\
220\end{array}$ & $\begin{array}{l}859 \\
212\end{array}$ & $\begin{array}{l}796 \\
215\end{array}$ & $\begin{array}{l}855 \\
256\end{array}$ & $\begin{array}{l}709 \\
199\end{array}$ & $\begin{array}{l}986 \\
236\end{array}$ & $\begin{array}{r}1065 \\
297\end{array}$ & $\begin{array}{r}1180 \\
319\end{array}$ & $\begin{array}{l}926 \\
218\end{array}$ \\
\hline
\end{tabular}

On problems about the job- "A fixed half day in the treatment room was not very valuable. Better to carry out small procedures as and when necessary." "Follow up of treated cases was difficult when patients resorted to their normal doctor at their leisure-did a failed follow up appointment imply successful treatment or a dissatisfied customer?" "My levels of suspicion and experience were not as high as those of the partners, so I am sure that patients did not always receive as rapid or as well organised management as they might had they consulted my seniors." "The scheme may not have been as rewarding for the partners as it was for me."

On personal development-"It was only by discussing cases fully with the partners and encouraging their feedback and criticism that I was able to feel more confident in my management decisions ... . in contrast with the hospital structure where one is under direct supervision." "I was able to see how illnesses affected their life styles and the effect on relatives and friends . . . instead of regarding a patient as a single case of chest pain, to understand the patient's worries and fears as a result." "As my confidence in my clinical experience improved I felt more at ease to explore new avenues in my consultations, often with stimulating and striking results." "I became incensed by my hospital colleagues' attitudes towards general practitioners." "Initial ignorance (about non-medical services) was only slowly replaced by a desire to share the care of patients between the team."

On after effects- "Back in hospital my main aim will be to keep the patients more informed during their stay." "I think this [kind of scheme] will improve the relationship between the hospital and community, and that has to be good for the patient."

After completing the preregistration year two of the general practice house officers decided to go into general practice, including one who had been considering this as a serious possibility from the beginning. The others still wanted to pursue careers in surgery, obstetrics and gynaecology, anaesthetics, or chest medicine. 


\section{Discussion}

The special contribution which general practice could offer had several components. Firstly, the diagnosis and management of acute and chronic conditions outside the hospital, many of them rarely seen within it. Secondly, investigating and prescribing in general practice. Thirdly, many aspects of preventive care. Fourthly, the relation of primary care to the hospital services. Fifthly, when and how to mobilise the services available in the community. Sixthly, and lastly, understanding the inherent differences between general practice and hospital practice in interviewing patients.

In practical terms the scheme worked smoothly, and we believe that it has been an educational success. Having less time in medicine and surgery does not seem to have been an important loss to the house officers. The four months in Lisson Grove brought changes in their attitudes and behaviour, described in their own commentaries and observed by us, of a kind which we think should be assessed in any form of evaluation devised for the whole preregistration period. Many of the aims set out in the General Medical Council's 1980 Recommendations seem to have been met during the time spent in general practice.

No harm has been done to the house officers' careers by taking part in the experiment: they have had no special difficulty in obtaining posts for which they have subsequently applied, and at interview their unusual experience has aroused great interest.

We see six factors as particularly important in the success of the experiment. The first, and most vital, was probably the desire of everyone concerned that it should succeed. Secondly, special mention should be made of the friendly cooperation of all the staff of the practice and health centre. The third was the strong motivation and sensible behaviour of the house officers themselves. Fourthly, it was important that the practice was well equipped, worked in close liaison with other services, was experienced in teaching, and had time in which to teach. The presence of a trainee proved on balance to be an advantage. Fifthly, a period shorter than four months would have been unsatisfactory: only in the final month did most of the house officers become able to adapt to the novel work setting of the practice. Finally, the close involvement of the department of general practice offered a link with the medical school, facilities for the computer analysis of clinical activities, and a good library. It also provided for the house officers a tutor who understood the clinical problems they were facing but who was not directly concerned with these problems at a practical level. In the weekly departmental tutorials it was possible to think around them and to generalise their teaching potential.

The practice was undoubtedly put under some strain. Though the house officers required much more supervision than trainees, there was no financial recompense to the principals. Continuity of care for patients was compromised by the frequent change of house officer; not all the partners were happy about the effect of this, and it might be more of a problem in a practice with a smaller turnover of patients. Since it is inevitable, this issue should be considered carefully by any general practitioner who is thinking of taking part in a similar scheme.

After a very favourable report to London University by the regional postgraduate dean in 1984 , the rotation became established - subject to the five yearly review required for all preregistration posts.

The next step must be to produce evidence of a more objective kind that it is valuable to use general practice as a preregistration setting, and we hope that other medical schools will feel encouraged to mount their own experiments.

We thank the North West Thames Regional Health Authority; the special trustees of St Mary's Hospital; Dr John Lister, the regional postgraduate dean; Professor Arthur Crisp, former dean of the faculty of medicine; and the personnel department of St Mary's Hospital for their help in getting the experiment off the ground. For making it work we are grateful to Dr A Elder, Dr M Constantinidou, and Dr J Wilton, their practice staff, and the staff of the health centre. For undertaking the coding, teaching the general practice house officers how to code, and making computer analyses we are indebted to Miss Pat White, Miss Frances Hanson, and Mrs Tamara Stephan

Accepted 4 April 1985

\section{Clinical curio: birth defects from cursing? A case report}

Twenty five years ago Turner reported on an infant born with severe reduction deformities of the limbs, for which no normal cause could be identified; the mother's mother, angry at her daughter for becoming illegitimately pregnant, had cursed her, predicting that she would give birth to a baby without limbs.' A parallel case came to my attention in Sri Lanka.

The boy was born in 1980 with complete absence of arms and severe defects (talipes equinovarus) of both feet. He died 20 months later, six months before my investigation began. I obtained a photograph of the baby and a report of his examination immediately after birth, both of which documented the deformities.

According to his mother the pregnancy had been entirely normal. She had had no illness and had taken no drugs or alcohol during the pregnancy. Hospital records showed that delivery had occurred normally at full term. She and her husband were unrelated (as they came from the same village a remote relationship could not be discounted). A thorough review of their families elicited no other instance of birth defects. Thus it appeared that none of the commonly recognised causes of birth defects-illness, teratogenic drugs, or genetic factors-had occurred in this case.

The infant's father, together with his brother, had murdered an enemy six years before the boy's birth by cutting off his limbs with a sword. A report of the postmortem examination of the murdered man confirmed that three limbs had been severed, although some doubt surrounded the fourth limb.

Afterwards, the mother of the murdered man repeatedly cursed the boy's mother, saying that she would be punished for her husband's crime by having a deformed baby. The woman who was claimed to have made the curse denied the accusation, saying that she had merely asked the gods to punish the family; but her daughter remembered her mother cursing the family, although she did not recall any prediction of a deformed child.

The murder and subsequent cursing troubled the boy's mother. As a Buddhist, she was afraid that the murdered man might be reborn as her baby, perhaps deformed. Her first pregnancy after the murder produced a normal girl, and she began to think that the curse had somehow been neutralised. She and her husband were dismayed, therefore, but not entirely surprised, when her next baby was deformed.-IAN STEVENSON, professor of parapsychology, Cambridge.

1 Turner l:K. Teratogenic effects on the human firetus through maternal emotional stress. Report of a case. Hed 7 . I ust 1960;47:2):502-3.

How far back into early childhood can an adult's memory go to recollect people and events?

Most adults do not claim to be able to recollect much in the way of events from before the age of about 5 , but it is to be expected that isolated events, especially of emotional importance, such as road accidents or admissions to hospital, may be recollected with diminishing degrees of success in the preceding couple of years. The belief of Freud, that nothing once formed in the mind is ever lost, is no longer plausible and simply reflected ideas that were common to his time. We now realise how imperfect recollection always is, and that it is largely a construction at the time of recall of what was likely to have happened. It is difficult to design checks of accuracy for what may be claimed to be recollection of very early events, the supposed recall having usually been rehearsed many times before. Claims have often been made that, through "age regression" as a consequence of suggestions during hypnosis, events may be recalled from early life, even back to the moment of birth (or the moment of conception, I have heard seriously advocated). I think these claims must be regarded as having a basis only in the gullibility of the enthusiastic hypnotist. There is no conclusive evidence that hypnotised people, regressed or not, are able to recall more information from either recent or long past events than can non-hypnotised people. '-IAN OSWALD, professor of psychiatry, Edinburgh.

1 Wagstaff GF. Hypnosis and witness recall: a discussion paper. $J R$ Soc Med 1982;75:793-8. 